NASA Technical Memorandum 106583

AIAA-94-2955

\title{
Mixing and Noise Benefit Versus Thrust Penalty in Supersonic Jets Using Impingement Tones
}

Ganesh Raman

NYMA, Inc.

Engineering Services Division

Brook Park, Ohio

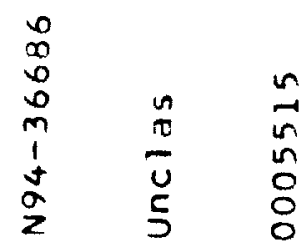

and

Edward J. Rice

National Aeronautics and Space Administration

Lewis Research Center

Cleveland, Ohio

Prepared for the

30th Joint Propulsion Conference

cosponsored by the AIAA/ASME/SAE/ASEE

Indianapolis, Indiana, June 27-29, 1994

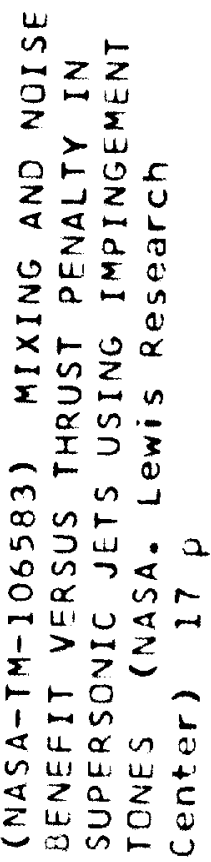




\title{
MIXING AND NOISE BENEFTT VERSUS THRUST PENALTY IN SUPERSOINC JETS USING IMPINGEMENT TONES
}

\author{
Ganesh Raman \\ NYMA, Inc. \\ Engineering Services Division \\ Brook Park, Ohio 44142 \\ and
}

Edward J. Rice*

National Aeronautics and Space Administration

Lewis Research Center

Cleveland, Ohio 44135

\begin{abstract}
This paper reports the results of an experimental investigation on the effect of impingement tones generated by obstacles of various geometries on the spreading of a supersonic jet flow. A rectangular supersonic jet was produced using a convergent-divergent nozzle that was operated near its design point (with shocks minimized). The immersion of obstacles in the flow produced an intense impingement tone which then propagated upstream (as feedback) to the jet lip and excited the antisymmetric hydrodynamic mode in the jet, thus setting up a resonant self-sustaining loop. The violent flapping motion of the jet due to excitation of the antisymmetric mode, combined with the unsteady wakes of the obstacles, produced large changes in jet mixing. It was possible to control the frequency and amplitude of the impingement tone excitation by varying the nozzle-to-obstacle distance and the obstacle immersion. By proper shaping of the obstacles it was possible to reduce the thrust penalty significantly.
\end{abstract}

\section{Nomenclature}

a speed of sound

b streamwise extent of obstacle

A area

$D_{c}$ equivalent circular diameter, $\sqrt{4 A_{\epsilon} / \pi}$

$f$ frequency

h smaller exit dimension of rectangular nozzle

$\begin{array}{ll}\mathbf{k} & \text { integer } \\ \mathbf{l} & \text { larger exit dimension of rectangular nozzle } \\ \mathrm{L} & \text { length of obstacle } \\ \mathbf{M} & \text { Mach number } \\ \dot{m} & \text { mass flux } \\ \mathbf{n} & \text { integer, edgetone stage } \\ \mathbf{p} & \text { pressure } \\ \mathrm{St}(\mathrm{h}) & \text { Strouhal number }\left(\mathrm{f} / \mathrm{U}_{\mathrm{j}}\right) \\ \mathbf{t} & \text { maximum thickness of obstacle } \\ \mathrm{U} & \text { velocity } \\ \mathrm{U}_{\mathrm{c}} & \text { phase velocity } \\ \mathrm{U}_{\text {obuccte }} & \text { flow velocity sensed by obstacle } \\ \mathbf{x} & \text { axial coordinate } \\ \mathbf{y} & \text { transverse coordinate } \\ \mathbf{z} & \text { longitudinal coordinate } \\ \rho & \text { density } \\ \gamma & \text { ratio of specific heats } \\ \tau & \text { thrust }\end{array}$

\section{Subscripts}

$\begin{array}{ll}\text { a } & \text { ambient } \\ \text { j,e } & \text { jet exit conditions } \\ \text { o } & \text { plenum } \\ \text { s } & \text { static } \\ \text { t } & \text { pitot }\end{array}$

\section{Superscripts}

* nozzle throat conditions

*NASA Lewis Distinguished Research Associate, retired. 


\section{INTRODUCTION}

There is a renewed interest in supersonic jet mixing due to the high speed civil transport (HSCT) program.' Several methods have been used to bring about jet mixing enhancement. For example, the use of tabs (Ahuja and Brown, ${ }^{2}$ Zaman et al. ${ }^{3}$ ), the use of counterflow (Strykowski et al. ${ }^{4}$ ), and the use of acoustic excitation (Lepicovsky et al.5), have shown that it is possible to bring about dramatic changes in the spreading rate of the jet. The idea of using acoustic feedback from natural or induced screech sources with potential applications in the design of jet mixer noise suppressors was described by Rice $^{6}$ (U.S. patents pending). Demonstation experiments on "induced screech" excitation were conducted by Rice and Raman. ${ }^{7,8}$ The "induced screech" concept is based on a class of tones created by flow impinging on surfaces. In the past such tones have been referred to in a broad sense as "edgetones". There has been considerable work on edgetone generation (Powell,' Rockwell, ${ }^{10}$ Crighton, and Krothapalli et al. ${ }^{12}$ ), however, the only work to use edgetones for jet mixing enhancement was the one by Krothapalli et al. ${ }^{12}$ The present method does not strictly fall under the category of edgetones but a variation of the edgetone known as a "ringtone" (Blake ${ }^{13}$ ). The ringtone in the traditional sense consists of a ring set concentrically with the axis of a circular jet. The method presented in this paper can be thought of as a twodimensional counterpart of a ringtone. Two obstacles were placed on either side of a rectangular supersonic jet. The immersion of these obstacles into the flow produced an intense impingement tone which then propagated upstream (as feedback) to the jet lip and excited the antisymmetric hydrodynamic mode in the jet, thus setting up a resonant self sustaining loop.

It is important to note that it is also possible to produce tones without obstacles, for example, screech tones from choked jets. Such tones have been studied by several researchers including Powell, ${ }^{14}$ Glass, ${ }^{15}$ Tam, ${ }^{16} \mathrm{Krothapalli}$ et al, ${ }^{17}$ Rice and Raman, ${ }^{7}$ and Raman and Rice. ${ }^{18}$ Note that in such cases the shocks in the flow can be thought of as being the obstacles. Therefore in this paper the impingement tone is referred to as "induced screech".

Our previous work ${ }^{7,8}$ used square obstacles (with one edge bevelled) with $L=76.2 \mathrm{~mm}$ and showed that it was possible to get a large mixing benefit. However, the mixing had to be paid for by a thrust penalty of almost $20 \%$ of the jet's ideal thrust. The thrust penalty cannot be ignored if the "induced screech" technique is to be adapted for practical applications. Quite obviously, it is necessary to explore ways to achieve mixing with a much lower thrust penalty, and that is the objective of the present study. In the present work results from the use of obstacles of various shapes will be discussed. The effect of obstacle shape on the induced tone amplitude, the mixing enhancement and the thrust penalty will be evaluated.

\section{EXPERIMENTAL DETAILS}

\section{A. Experimental Apparatus}

\section{A1. Jet Facility}

A schematic representation of the supersonic jet facility is shown in Figure 1. The $76 \mathrm{~cm}$ diameter plenum tank was supplied by compressed air at pressures up to $875 \mathrm{kPa}$ (125 Psig) at $80^{\circ} \mathrm{F}$. After passing through a filter that removed any dirt or dust, the air entered the plenum axially where it was laterally distributed by a perforated plate and a screen. Two circumferential splitter rings that contained acoustic treatment (Kevlar) removed upstream valve noise. The flow was further conditioned by two screens before undergoing two area contractions of 3.5 and 135 . The nozzle included a circular to rectangular transition and a converging-diverging nozzle contour, all integrated into one piece. The area ratio of the convergence, $\frac{A_{\text {chele }}}{A^{*}}$, was 2.38 over a length of 20.25 cm. The divergence area ratio, $\frac{A_{e}}{A^{*}}$, was 1.128 over a length of $2.125 \mathrm{~cm}$. The nozzle exit dimensions were $14.1 \times 68.1 \mathrm{~mm}$ yielding an aspect ratio of 4.82 . Note that the convergence-divergence occurred only in one direction $(y)$ with straight side walls. The nozzle, probe traversing mechanism and other reflective surfaces in the nearfield were covered with acoustically absorbent foam. The acoustically absorbent material used was open cell polyurethane foam. The material was $0.635 \mathrm{~cm}$ thick (uncompressed). Two layers of this material were used. The idea was to minimize strong reflections from the nozzle and plenum. The acoustically absorbent material is known to be very effective in absorbing incident sound at frequencies over $1000 \mathrm{~Hz}$. However, when several layers are used lower frequencies can also be absorbed.

\section{A2. Screech Inducing Obstacles}

Figure 2 shows the nozzle with the obstacles located 
slightly downstream. Each obstacle was instrumented with a total pressure tap and a strain gage to determine the pressure and axial force exerted by the jet flow on the obstacle respectively. The present study was conducted for obstacles of various geometries. The obstacle crosssections and dimensions are described in Table I. The cross-sections of the obstacles tried were: (A) No obstacles, (B) Square Bevelled, (C) Circular, (D) Elliptical, (E) Wedge, (F) Diamond airfoil, and (G) Lenticular airfoil. All the obstacles described in Table I had a length, $L$, of $38.1 \mathrm{~mm}$, and a thickness, $t$, of 3.175 mm. The streamwise extent of the obstacles varied depending on shape. For one shape (B) a limited set of experiments were carried out for three different obstacle lengths of 12.7, 38.1 and $76.2 \mathrm{~mm}$. The intermediate length obstacles $(38.1 \mathrm{~mm})$ produced the most mixing. Thus, obstacles of various shapes, all having the same length of $38.1 \mathrm{~mm}$ were evaluated. The obstacles will be referred to either by the alphabetical notation or by their shape or both in the text of this paper.

\section{A3. Instrumentation}

A $0.64 \mathrm{~cm}$ (B \& K) microphone located at the jet exit (see Figure 2) was used to obtain sound pressure levels and spectra. The microphone was omnidirectional (according to manufacturer specifications) within $\pm 1 \mathrm{~dB}$ up to $10 \mathrm{KHz}$ and within $\pm 3 \mathrm{~dB}$ up to $20 \mathrm{KHz}$. The microphone was calibrated using a B \& $\mathrm{K}$ pistonphone calibrator and the calibration was corrected for day to day changes in atmospheric pressure. Note that the sound pressure levels reported in this paper are in $\mathrm{dB}$ relative to $20 \mu \mathrm{Pa}$ (the threshold of human hearing). The strain gages were calibrated by hanging known weights from the obstacle supports with the obstacles clamped in place. The calibration curve was linear for the force range encountered in the present work. A linear curve-fit for a typical calibration equation relating the axial force, $F$, on the obstacle to the voltage, $V$, from the stain gage was $F(k g)=0.456 \mathrm{~V}$ (volts) $+9.51 \times 10^{-4}$ with a variance of 0.00684 and a maximum deviation of 0.00958 . A pitot probe with an $0 . d$. of $0.8 \mathrm{~mm}$ was used for the flowfield measurements. The pitot probe was connected to a pressure transctucer by a $0.8 \mathrm{~mm}$ i.d. tygon tube. Three different pressure transducers having a maximum range of $350 \mathrm{kPa}$ (50 Psig), $105 \mathrm{kPa}$ (15 Psig) and $35 \mathrm{kPa}$ (5 Psig) respectively were used for the measurements. The centerline pressure at every axial station was used as a guide to select the transducer of an appropriate range for maximum sensitivity.

\section{A4. Schlieren System}

A focusing schlieren system similar to the one described by Weinstein ${ }^{19}$ was used for flow visualization. The schlieren system operated with a strobe in a swept phase mode to produce motion pictures of the flapping mode of the jet. The control system for the schlieren apparatus was modeled after Wezien and Kibens ${ }^{20}$ and was also used with success in our earlier work. ${ }^{7,18}$ The operation of the strobed schlieren system can be summarized as follows: First, the vertical synchronization pulse from the video camera was sensed. Then, a phase delay was started at the first zero crossing of the screech tone, which was measured by a microphone mounted on the nozzle. Finally, after the prescribed phase delay, the strobe was fired. With a fixed phase delay the motion of the flapping jet could be stopped for viewing. The phase delay could also be continously swept through one period of screech with the video displaying the flapping motion of the jet instability.

\section{B. Experimental Procedure}

The converging-diverging rectangular nozzle was operated at its design Mach number ( 1.392) to minimize natural screech that could interfere with the induced screech. The induced screech was caused by obstacles located on either side of the longer dimension of the nozzle. The jet was first turned on with the obstacles placed outside the flow. The obstacles, which were instrumented with pitot probes and strain gages, were then gradually moved into the flow. At a given axial station the obstacles were immersed to the transverse locations where the normalized velocity measured by the probe on the obstacle, $\mathrm{U}_{\text {obmact }} / \mathrm{U}_{\mathrm{j}}$, was 0.36 or 0.72 . For comparative purposes the flowfield data for obstacles of various geometries was taken at the same axial location $(x / h=7.7)$ of the obstacles and the same obstacle immersion $\left(\mathrm{U}_{\text {obmecte }} / \mathrm{U}_{\mathrm{j}}=\right.$ 0.72).

For the various obstacle shapes the induced tone was monitored at the jet exit. Strain gages mounted on the obstacle supports were used to obtain the axial force experienced by the obstacles. The entire cross-section of the jet was surveyed at two downstream locations, $x / D_{c}$ of 5 and 11. This survey was performed using a total pressure probe. In this paper the induced tone amplitude (measured using a microphone at the jet exit), an estimate of the thrust loss (from the force on the obstacles), and an estimate of the mixing benefit (from the integration of the pressure survey) will be compared. 


\section{DISCUSSION OF RESULTS}

The initial part of the discussion will focus on the impingement tone produced by the obstacles. The effect of the impingement tone on the noise spectrum of the supersonic jet will be discussed. Then, the effect of the axial placement and immersion of the obstacle on the frequency and amplitude of the impingement tone will be discussed. Following this discussion the flow visualization results for some cases of various axial obstacle placements and immersions will be described. Detailed cross-sections of the jet showing Mach number contours for the various shapes of obstacles will be described at two measurement stations. Finally the relationship between the impingement tone amplitude, mass-flux enhancement, and thrust penalty will be described and the significance of these results for potential applications will be discussed.

\section{A. Impingement Tone Characteristics}

Figure 3 shows a sound pressure level spectrum obtained using a microphone at the jet exit for two cases, the first case being the natural jet and the second case being the induced tone case. The natural jet was obtained by operating a convergent-divergent nozzle at its design point where shocks are minimized (but not eliminated). The natural jet spectrum shows a relatively weak screech tone with a sound pressure level of $144 \mathrm{~dB}$ at $\mathrm{St}(\mathrm{h})=0.15$. When obstacle $G$ is introduced into the flow at an axial location of $x / h=7.7$, and at an immersion where $\mathrm{U}_{\text {drenced }} / \mathrm{U}_{\mathrm{j}}=0.72$ the tone amplitude is intensified (159 $\mathrm{dB})$ at the same Strouhal number $(0.15)$.

It is interesting to note that besides the tones, the character of the two spectra are different. For the natural jet under ideally expanded conditions (shocks minimized), one would expect insignificant shock associated broadband noise. The only significant contributions are from the jet mixing noise and the broadband noise that is associated with the finer scales of turbulence. In contrast, when the obstacles are immersed there are noise contributions from all the mechanisms. Thus, the broadband noise levels are higher when the obstacles are immersed.

The fact that the impingetwent tone excites the jet in an antisymmetric mode was verified by $a$ pair of microphones located on either side of the narrow dimension of the nozzle. The phase difference between the two microphones (obtained from the crosspectrum phase) was about $180^{\circ}\left( \pm 5^{\circ}\right.$ measurement and positioning accuracy).

An edgetone is conventionally generated by allowing a jet to impinge on a wedge shaped obstacle. Such a technique was used by Krothapalli et al. ${ }^{12}$ to enhance mixing in a multi-jet configuration. The wedge, however, was placed in one jet and the tone generated enhanced mixing in all four jets. Note that a wedge placed right in the middle of a jet would cause significant losses. In the present work the obstacle was only partially immersed in the flow from either side of the jet. The fact that the screech is induced by the edgetone mechanism is clear from Figures 4(a) and 4(b). In Figure 4 the Strouhal number $\left(\mathrm{fb} / U_{j}\right)$ of the screech tone induced at the jet lip is plotted versus a dimensionless nozzle-to-obstacle distance. Although the data are for obstacle $B(L=76.2 \mathrm{~mm})$, they reproduce quite well for the other shapes. The numbers above the experimental data represent the tone amplitudes ( $d B$ relative to $20 \mu \mathrm{Pa}$ ) measured at the jet lip. The difference between Figures 4(a) and 4(b) lies in the immersion of the obstacles. The obstacle immersion was such that both obstacles sensed a normalized flow velocity, $U_{\text {counces }} / U_{j}$ of 0.36 (Figure 4(a)) or 0.72 (Figure 4(b)). For both cases there is a simultaneous presence of multiple frequencies which were not harmonically related. Different modes or "edgetone staging" is observed. Values of expected edgetone frequencies based on Powell's' theory were calculated using:

$$
n d f=x / U_{c}+x / a
$$

where $f$ represents the frequency of the tone, $n$ denotes the stage. The nozzle to edge distance, $x$ and the phase velocity of the coherent disturbances, $\mathrm{U}_{e}$, along with the speed of sound, a, determines the frequency of the edgetone. Note that in a very low speed flow $a>U_{c}$ and $n / f=x / U_{c}$ is sufficient to calculate the frequency. This is not so in a high speed jet. The calculated stage Strouhal numbers ( $\left(h / U_{j}\right.$ ) based on the above equation are shown as dashed lines in Figure $4(a, b)$ for several stages. A phase velocity, $U_{c} / U_{j}$, of 0.55 produced the best agreement for 4(a) whereas an assumed phase velocity, $U_{\mathrm{c}} / \mathrm{U}_{\mathrm{j}}$, of 0.44 produced the best agreement for $4(\mathrm{~b})$. Both immersions produced tones in the Stroubal number range $(0.15-0.2)$ most effective for enhancing jet mixing. The tone amplitudes are very high for $n=3$. $A$ plausible explanation could be that in addition to the requirements of Eqn (1), a standing wave could be formed between the obstacle and the nozzle lip. The frequency of such a standing wave is 


$$
f=\frac{a k}{2 x}
$$

A double resonance will occur when equations (1) and (2) are satisfied simultaneously. For the present set of data it appears that such a resonance occurs for $n=k=3$. A similar observation was also made by Fox et al. ${ }^{21}$ for the case of a jet impinging on a flat plate. In addition, the sound pressure levels produced by greater immersion of the obstacles were higher and were expected to cause higher mixing. Note that the greater immersions would also represent higher values of thrust loss. It is this mixing benefit versus thrust penalty that will be the focus of later sections. Although the mechanisms for natural and induced screech are fairly well understood and the frequency correlates reasonably well with the shock spacing (natural screech) or the nozzle-to-obstacle spacing (induced screech), it is difficult to define the parameters that control the amplitude.

The impingement tone characteristics for obstacles of various shapes at an obstacle location of $x / h=7.7$ and an immersion at which the obstacles sensed a normalized velocity, $U_{\text {obsenct }} / U_{j}=0.72$, are given in Table II. It was at this axial location $(x / h=7.7)$ that the induced tone frequency matched the natural flow instability and consequently had the maximum effect on the spreading of the jet. The effect on the jet spread is discussed in Section C. It is important to emphasize that despite the similarities between the phenomenon under study and the edgetone, there exist differences between them. For example, in the present case one side of the obstacle senses a higher velocity than the other and there could be a "nozzle effect" when two aerodynamically shaped obstacles are used on either side of the jet causing local acceleration (or deceleration) of the flow.

\section{B. Flow Visualization}

Figure 5 is a strobed schlieren photograph of the natural jet. The convergent-divergent nozzle is operated at design conditions (with shocks minimized). The ideally expanded jet is seen in the photograph. Note that since it is not possible to eliminate shocks completely in a rectangular jet there is sotme residual screech that causes some flapping motions in the jet. Figure 6 shows schlieren photographs of the jet with obstacles (shape B, $L=76.2 \mathrm{~mm}$ ) at $\mathrm{x} / \mathrm{h}=2.9$ for two different obstacle immersions $\left(U_{\text {obrecte }} / U_{j}=0.36\right.$ and 0.72$)$. From the picture small wavelength (high frequency) oscillations are visible in such a jet. Figures 7 and 8 show the same type of photographs as Figure 6 , but for other $x / h$ locations $(x / h=5$ and 7.7 respectively) of the obstacles. From Figures 6 through 8 it is seen that a larger nozzle-toobstacle $(\mathrm{x} / \mathrm{h})$ distance excites waves of a larger wavelength (lower frequency). In addition, the amplitude of the oscillations is seen to increase as the immersion is changed from $U_{\text {obrack }} / U_{j}=0.36$ to 0.72 . These photographs provide visual proof that it is possible to excite the jet at various frequencies and amplitudes of the antisymmetric mode by varying the axial location and the immersion of the obstacles, (i.e., the trends shown in Figure 4(a,b) are confirmed visually).

\section{Description of the Mean Flowfield}

Figures 9 and 10 show the Mach number contours measured at $x / D_{0}=5$ and 11 respectively for the various cases under consideration. The inner and outermost contours are specified. In addition the crossectional shape of the obstacle is indicated in the figure. The notation and obstacle geometries are described in Table I. For all cases the obstacle length (L) was $38.1 \mathrm{~mm}$. For each case the obstacles were located at $x / h=7.7\left(x / D_{0}=\right.$ 2.85) at an immersion where the obstacles experienced a normalized flow velocity of $U_{\text {obracke }} / U_{j}=0.72$. The Mach numbers were obtained from the measured pitot pressures using:

$$
M=\sqrt{\left(5 *\left(\frac{P a}{P_{1}+P a}\right)^{-0.2057}-1\right)}
$$

Note that it was assumed that $\gamma=1.4$ and that the local static pressures could be approximated by the ambient room pressure. Such an approximation is fairly accurate at $x / D_{c}=11$ (Figure 10) but not so for the data at $x / D_{e}$ $=5$ (Figure 9). However, the data is still good for comparative purposes. The obstacles are seen to produce a significant increase in jet spreading. Note the change in scales between Figures 9 and 10. Also note that for obstacles B,C the supporting rods (see Figure 2) were cylindrical $(3.175 \mathrm{~mm}$ dia) whereas for obstacles $D$ through $G$, the supports were airfoil shaped struts. Thus not only is the drag low due to these but the spreading of the jet along the supporting rods is minimized. There is bence a marked change between the cross-section distortion for obstacles $B$ and $C$ versus that for $D$ through G. 


\section{Tone Amplitude, Thrust Loss and Mixing} Enhancement

The induced tone amplitude with the various obstacles in place was measured using a microphone located at the jet exit. The thrust loss estimate was obtained in the following manner: First, the ideal thrust of the jet issuing from a convergent-divergent nozzle operating at its design point was calculated using:

$$
\tau=A^{*} P_{0} \sqrt{\frac{2 \gamma^{2}}{\gamma-1}\left(\frac{2}{\gamma+1}\right)^{(\gamma+1)(\gamma-1)}\left[1-\left(\frac{P_{e}}{P_{0}}\right)^{(\gamma-1) / \gamma]}\right.} \text { (4) }
$$

where $\tau$ represents the thrust, $A^{*}$ the throat area, $\gamma$ the ratio of specific heats, and $P_{e}$ and $P_{0}$ represent the exit pressure and plenum pressure respectively. Then, the axial force exerted by the jet on the obstacles was obtained by a direct measurement using strain gages mounted on the obstacle supports. Finally, the ratio obtained by dividing the force sensed by the obstacles by the jet's ideal thrust expressed as a percentage provided the thrust loss number that will be discussed in this section. The jet's ideal thrust was $26.45 \mathrm{Kg}$ and the force on the obstacles varied depending on the shape and immersion of the obstacles.

The mass-flux ratio which is used here as an indicator of jet mixing enhancement was obtained using the pitot tube data and was calculated as follows:

$$
\frac{\dot{m}}{\dot{m}_{e}}=\iint \frac{(\rho U) d y d z}{\rho_{e} U_{e} A_{e}}
$$

where

$$
\frac{\rho U}{P_{e} U_{c}}=\frac{P_{s}}{P_{e}} \frac{M}{M_{e}}\left(\frac{1+0.2 M^{2}}{1+0.2 M_{e}^{2}}\right)^{0 . s}
$$

Note that $M$ is obtained from Eqn. 3 and $\gamma=1.4$. It was assumed that the local static pressure, $P_{3}$, could be approximated by the ambient static pressure, $P_{2}$. The mass-flux calculation method described above was used previously by Zaman et al. ${ }^{3}$

Figure 11(a) shows a plot of the thrust loss for a pair of obstacles versus the amplitude of the induced tone measured at the jet lip. The obstacles were located at $x / h$ $=7.7\left(x / D_{c}=2.85\right)$ at an immersion where the obstacles experienced a flow velocity of $U_{\text {obueces }} / U_{j}=0.72$. It is clear that by appropriate shaping it is possible to induce a very high amplitude tone at the jet lip with very little thrust loss. For example, the square obstacle (B) induces a screech tone of $157 \mathrm{~dB}$ at the jet lip with an associated thrust loss of $14.4 \%$. In contrast a shaped obstacle (G) can induce a tone of $159 \mathrm{~dB}$ with a $3.2 \%$ thrust penalty. However, it should be noted that the screech level at the lip alone is not a good enough indicator of the spreading rate of the jet due to the following: First, due to the saturation effect, beyond a certain level of screech amplitude there may be no further effect on the spreading of the jet. Second, the hydrodynamic effect of the obstacles (due to the unsteady obstacle wakes) needs to be considered. Therefore one would have to make detailed surveys downstream (such as the ones shown in Figures 9 and 10) to assess the combined effect of screech and the hydrodynamic effect of the obstacles.

Figure 11(b) shows a plot of the mass-flux ratio versus the amplitude of the screech tone induced at the jet lip. The axial location and immersion of the obstacles was the same as that described in connection with Figure 11(a). Mass-flux data is shown at $x / D_{0}=5$ (filled symbols) and $x / D_{c}=11$ (open symbols). From this figure it is very clear that the obstacle which induces the highest tone amplitude $(G)$ is not the one that produces the maximum increase in the mass-flux ratio. The square and circular cross-section obstacles with cylindrical supports provide the highest mass-flux values. Thus, it is to be recognized that the effect on the mass-flux ratio is not due to the screech tone alone but due to a combination of the screech tone and the unsteady wake of the obstacles and the obstacle supports.

Figure 11(c) shows the thrust loss versus mass-flux ratio for various obstacles. The mass-flux ratio measured at $x / D_{0}=5$ (filled symbols) and $x / D_{0}=11$ (open symbols) is plotted on the abscissa. It should be pointed out that the mass-flux ratio for the no-obstacle case was 1.64 at $x / D_{c}=5$ and 2.4 at $x / D_{c}=11$. For the obstacle cases the thrust loss value given is for a pair of obstacles. The obstacles that produce high mixing have a high thrust loss. The shaped obstacles have a substantially lower thrust penalty, but also produce lower mixing.

\section{E. Mixing Benefit Versus Thrust Penalty}

In order to make a quantitative comparison between the obstacles it is necessary to define a mixing benefit parameter that is adjusted for thrust loss. A mixing benefit parameter at any downstream station can be defined as given below: 


\section{Mixing Benefit Parameter $=$}

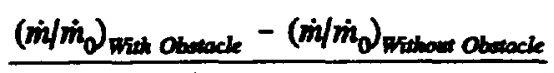

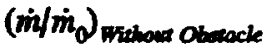

The difference between the mass flux ratios of the case with the obstacles and without the obstacles is really a measure of the mixing benefit. This is normalized by the mass flux ratio for the no obstacle case and is expressed as a percentage. Therefore one could say that by the introduction of the obstacle the mass flux ratio at a given downstream station is increased by a certain percentage of the no obstacle case. This will be referred to as the mixing benefit parameter. When this parameter is normalized by the percent thrust loss it provides a thrust loss adjusted mixing benefit parameter. This parameter is tabulated in Table III. This parameter is somewhat like an obstacle efficiency number. Higher values indicate more efficient obstacles. However the selection of obstacles should not be made based on this number alone. For example obstacle B which has a thrust loss adjusted mixing benefit of 2.15 has a mixing benefit parameter of 31.09 with a very high thrust penalty of $14.4 \%$. In contrast obstacle $F$ which has a thrust loss adjusted mixing benefit of 8.5 has a very low thrust penalty $(0.965 \%)$ but the mixing benefit parameter (8.2) is not attractive for practical applications. Obstacle $G$ appears attractive with a mixing benefit parameter of 17.03 and a thrust penalty of $3.2 \%$, yielding a thrust loss adjusted mixing benefit of 5.35 .

\section{F. Applicability - Noise Reduction in Mixer Ejectors}

Note that in practical applications the obstacles can be used when required and retracted at other times. For example, to rapidly mix the exhaust of a military aircraft in order to reduce its thermal signature, the obstacles need to be immersed only at critical times during combat. In applications relating to HSCT (High Speed Civil Transport) the technique could be used to satisfy the sideline noise requirements for takeoff and approach and withdrawn at other times." Although it may appear that the "induced screech" technique generates additional noise, the noise produced by the obstacles (induced screech noise) is easier to attenuate than jet noise. ${ }^{8}$ This is because this technique would be applied internal to a mixer ejector and the screech noise mainly propagates upstream, the screech noise can easily be suppressed.
The higher mixing produced by the obstacles will bring about a quick and rapid mixing of the primary and secondary streams and could make a short ejector feasible. In addition, it has been shown that by the use of this technique the mixing noise source is moved upstream. ${ }^{8}$ Thus the ejector length is effectively increased without increasing its physical dimensions.

\section{CONCLUDING REMARKS}

The concept of using impingement tones to enhance the mixing of a supersonic rectangular jet was explored further. Obstacles of various cross-sectional shapes were placed in the flow. The obstacles were placed at an axial station where the induced tone matched the natural flow instability. In addition, the obstacle immersion that produced the highest levels of excitation was used. The impingement tone excited the jet in the antisymmetric mode. The combination of this excitation and the effect of the wake of the obstacles caused significant changes in the jet cross-section and spreading rate. The main focus of this work was on evaluating mixing benefit and its relationship to the thrust penalty. A comparison between the various obstacle shapes was made using a mixing benefit parameter and a thrust loss adjusted mixing benefit parameter. The Lenticular airfoil (convex lens shaped) with diamond airfoil shaped supports was seen to provide the best results for the range of parameters tested in this study.

\section{ACKNOWLEDGEMENTS}

The authors would like to thank Mr. James Little (electronics), Mr. Rick Brokopp (facility operations), and Mr. Bill Ratvasky (optics) for their help in the experiments. Dr. K.B.M.Q. Zaman, and Mr. John M. Abbott provided constructive suggestions and encouragement. In addition, the authors would like to thank Ms. Tammy Langhals for her help in the production of this document.

\section{REFERENCES}

(1) Seiner, J.M., and Krejsa, E.A., "Supersonic Jet Noise and the High Speed Civil Transport," AIAA Paper 892358.

(2) Ahuja, K.K. and Brown, W.H., "Shear Flow Control by Mechanical Tabs," AIAA Paper 89-0994, 1989. 
(3) Zaman, K.B.M.Q., Reeder, M.F., and Samimy, M., "Control of an Axisymmetric Jet Using Vortex Generators," Phys. Fluids 6(2), Feb. 1994, pp. 778-793.

(4) Strykowski, P.J., Krothapalli, A., and Wishart, D., "The Enhancement of Mixing in High Speed Heated Jets Using a Counterflowing Nozzle, " AIAA Paper 92-3262, 1992.

(5) Lepicovsky, J., Ahuja, K.K., Brown, W.H., and Burrin, R.H., "Coherent Large-Scale Structures in High Reynolds Number Supersonic Jets," AIAA J., Vol. 25, 1987, pp. 1419-1425.

(6) Rice, E.J.NASA Lewis Research Center, "Jet Mixer Noise Suppressor using Acoustic Feedback," Patents pending, Application Numbers 08/046, 256 Filed 04/14/1993, and 08/194, 654, Filed 02/10/94.

(7) Rice, E.J., and Raman, G., "Enhanced Mixing of a Rectangular Supersonic Jet by Natural and Induced Screech," AIAA Paper 93-3263, 1993.

(8) Rice, E.J. and Raman, G., "Mixing Noise Reduction for Rectangular Supersonic Jets by Nozzle Shaping and Induced Screech Mixing," AIAA Paper 93-4322, 1993.

(9) Powell, A., "On the Edgetone," The Journal of the Acoustical Society of America, Vol. 33, No. 4, April 1961, pp 395-409.

(10) Rockwell, D., "Oscillations of Impinging Shear Layers," AIAA Journal, Vol. 21, No. 5, May 1983, pp 645-664.

(11) Crighton, D.G., "The Jet Edge-Tone Feedback Cycle; Linear Theory for the Operating Stages," Journal of Fluid Mechanics, Vol. 234, Jan. 1992, pp. 361-391.

(12) Krothapalli, A., Karamcheti, K., Hsia, Y., and Baganoff, D., "Edge Tones in High Speed Flows and their Application to Multiple-Jet Mixing," AIAA Journal, Vol. 21, No. 7, July 1983, pp. 937-938.

(13) Blake, W.K., "Mechanics of Flow-Induced Sound and Vibration, Vol. I: Geheral Concepts and Elementary Sources," Applied Mathematics and Mechanics, Vol. 17I, Academic Press Inc., New York, 1986.

(14) Powell, A., "On the Noise Emanating from a TwoDimensional Jet above the Critical Pressure," Aeronautical Quarterly, Vol. 4, Feb. 1953, pp 103-122.
(15) Glass, D.R., "Effects of Acoustic Feedback on the Spread and Decay of Supersonic Jets," AIAA Journal, Vol. 6, Oct. 1968, pp. 1890-1897.

(16) Tam, C.K.W., "The Shock-Cell Structures and Screech Tone Frequencies of Rectangular and NonAxisymmetric Supersonic Jets," Journal of Sound and Vibration, Vol. 121, No. 1, 1988, pp 135-147.

(17) Krothapalli, A., Hsia, Y., Baganoff, D., and Karamcheti, K., "The Role of Screech Tones in Mixing of an Underexpanded Rectangular Jet," Journal of Sound and Vibration, Vol. 106, No. 1, 1986, pp 119-143.

(18) Raman, G. and Rice, E.J., "Instability Modes Excited by Natural Screech Tones in a Supersonic Rectangular Jet," AIAA Paper 93-4321, 1993.

(19) Weinstein, L.M., "An Improved Large-Field Focusing Schlieren System," AIAA Paper No. 91-0567.

(20) Wlezien, R.W., and Kibens, V., "Influence of Nozzle Asymmetry on Supersonic Jets," AIAA Journal, Vol. 26, No. 1, Jan. 1988, pp. 27-33.

(21) Fox, M.D., Kuroska, M., Hedges, L., and Hirano, K., "The Influence of Vortical Structures on the Thermal Fields of Jets," J. Fluid Mech., Vol. 255, pp. 447-472, 1993. 
TABLEI DESCRIPTION OF OBSTACLE GEOMETRY

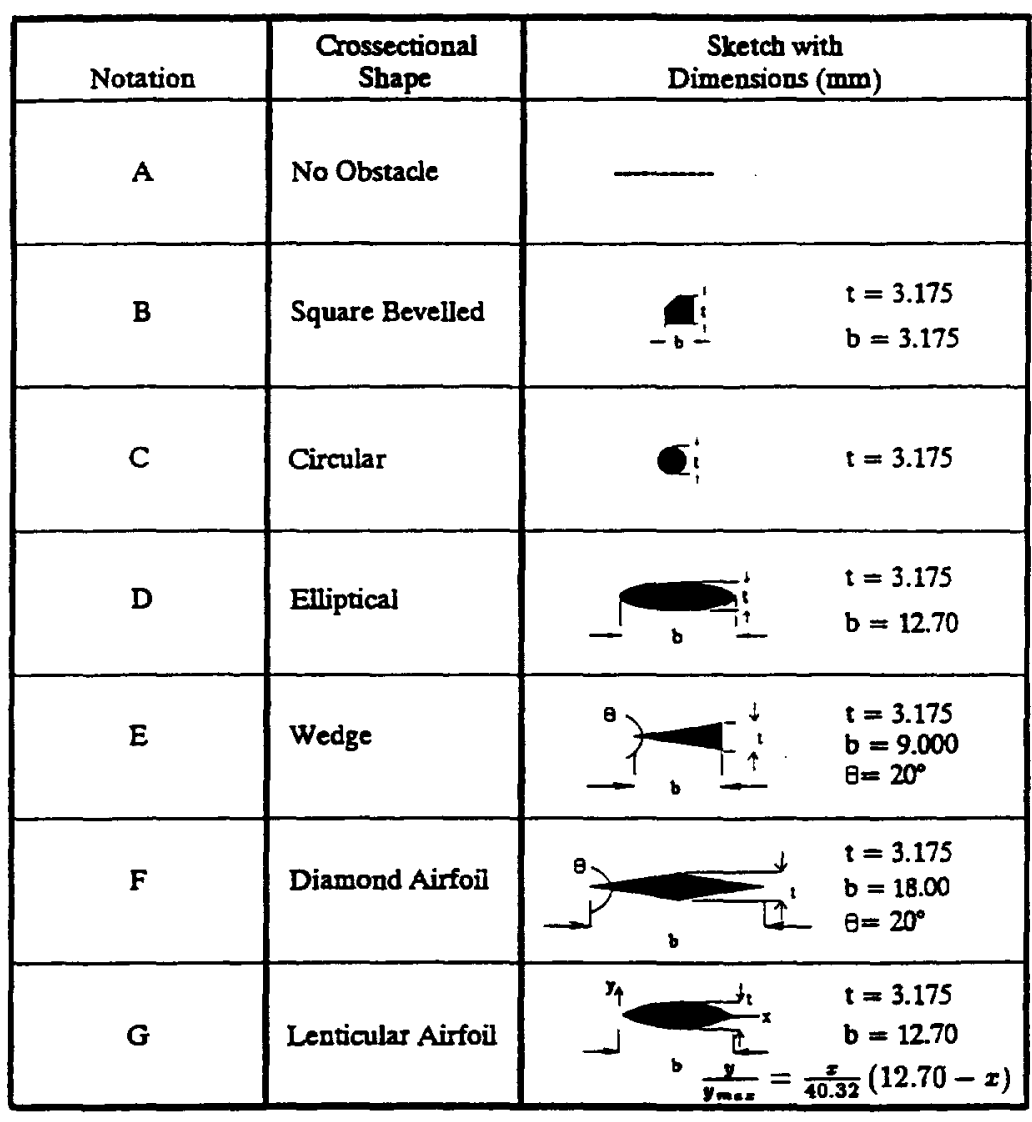

TABLE II IMPINGEMENT TONE CHARACTERISTICS FOR VARIOUS OBSTACLES (LOCATION $x / \mathrm{h}=7.7,\left(\pi / \mathrm{D}_{\mathrm{e}}=285\right)$ IMMIERSION $U_{\text {obstacle }}\left(U_{j}=0.72\right)$

\begin{tabular}{|c|c|c|c|}
\hline $\begin{array}{c}\text { Obstacle } \\
\text { (Notation and } \\
\text { Geometry) }\end{array}$ & $\underset{(\mathbf{H z})}{\mathbf{f}}$ & St(h) & $\begin{array}{c}\text { SPL (dB) } \\
\text { (measured at } \\
\text { jet lip) }\end{array}$ \\
\hline A No Obstacle & 5280 & 0.150 & 144.0 \\
\hline B & 5248 & 0.149 & 157.0 \\
\hline c & 5100 & 0.145 & 156.0 \\
\hline D & 5152 & 0.146 & 151.6 \\
\hline $\mathbf{E}$ & 5216 & 0.148 & 154.2 \\
\hline $\mathbf{F}$ & 5248 & 0.149 & 156.8 \\
\hline$G$ & 5280 & 0.150 & 159.0 \\
\hline
\end{tabular}


TABLE III COMPARISON OF MIXING BENEFIT

VERSUS THRUST LOSS

\begin{tabular}{|c|c|c|c|}
\hline Obstacle & $\begin{array}{c}\text { Thrust Loss } \\
\text { (\% of jet thrust) }\end{array}$ & $\begin{array}{c}\text { Mìing Benefit } \\
\text { Parameter } \\
\left(x \mathcal{D}_{e}=5\right) \\
\end{array}$ & $\begin{array}{c}\text { Mixing Benefit per } \\
\% \text { Thrust Loss } \\
\left(\mathrm{x} \mathrm{D}_{\mathrm{e}}=5\right)\end{array}$ \\
\hline A No Obstacle & -- & .. & - \\
\hline B & 14.400 & 31.09 & 2.15 \\
\hline C & 12.000 & 21.34 & 1.78 \\
\hline D & 1.450 & 6.64 & 4.57 \\
\hline $\mathbf{E}$ & 1.720 & 13.23 & 7.69 \\
\hline $\mathbf{F}$ & 0.965 & 8.20 & 8.50 \\
\hline $\mathbf{G}$ & 3.200 & 17.13 & 5.35 \\
\hline
\end{tabular}

Mixing Benefit Parameter $=\frac{\left(\dot{m} / \dot{m}_{0}\right)_{\text {With Obstacle }}-\left(\dot{m} / \dot{m}_{0}\right)_{\text {Without Obstacle }}}{\left(\dot{m} / \dot{m}_{0}\right)_{\text {Withous }} \text { Oberscle }} \times 100$

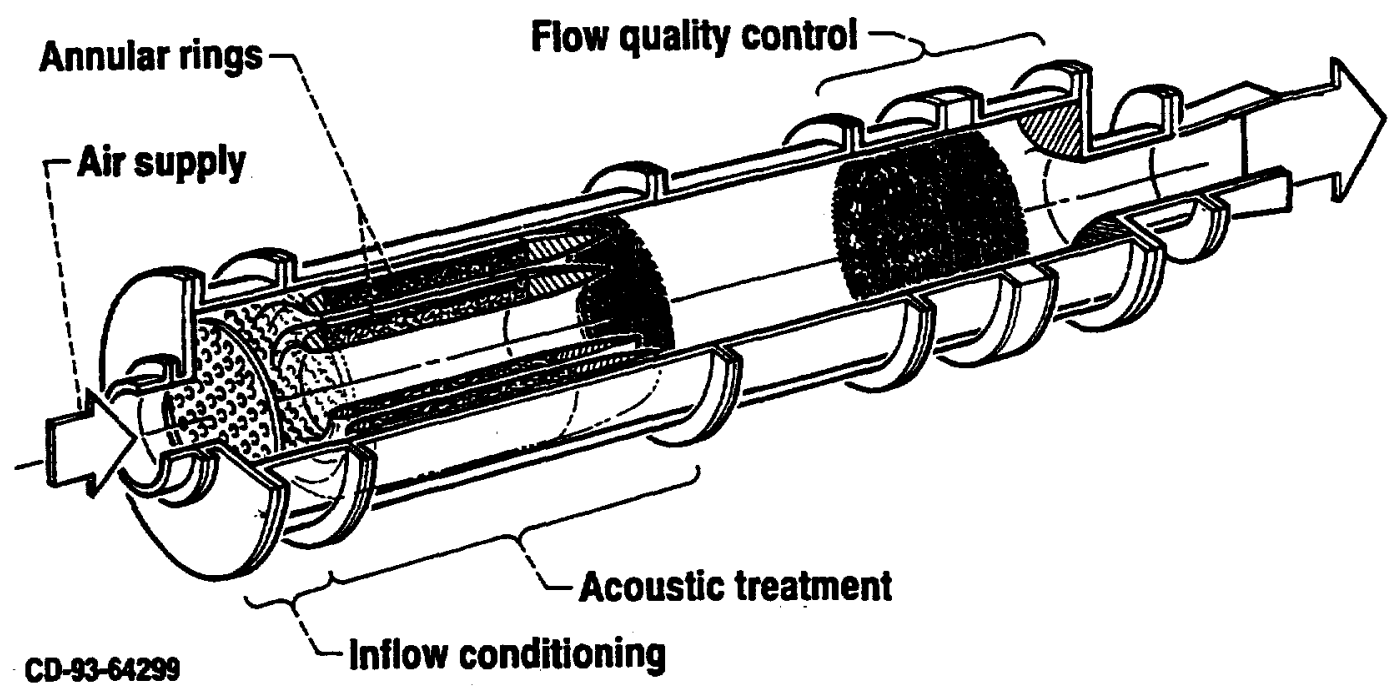

Figure (1) Schematic of supersonic jet facility. 


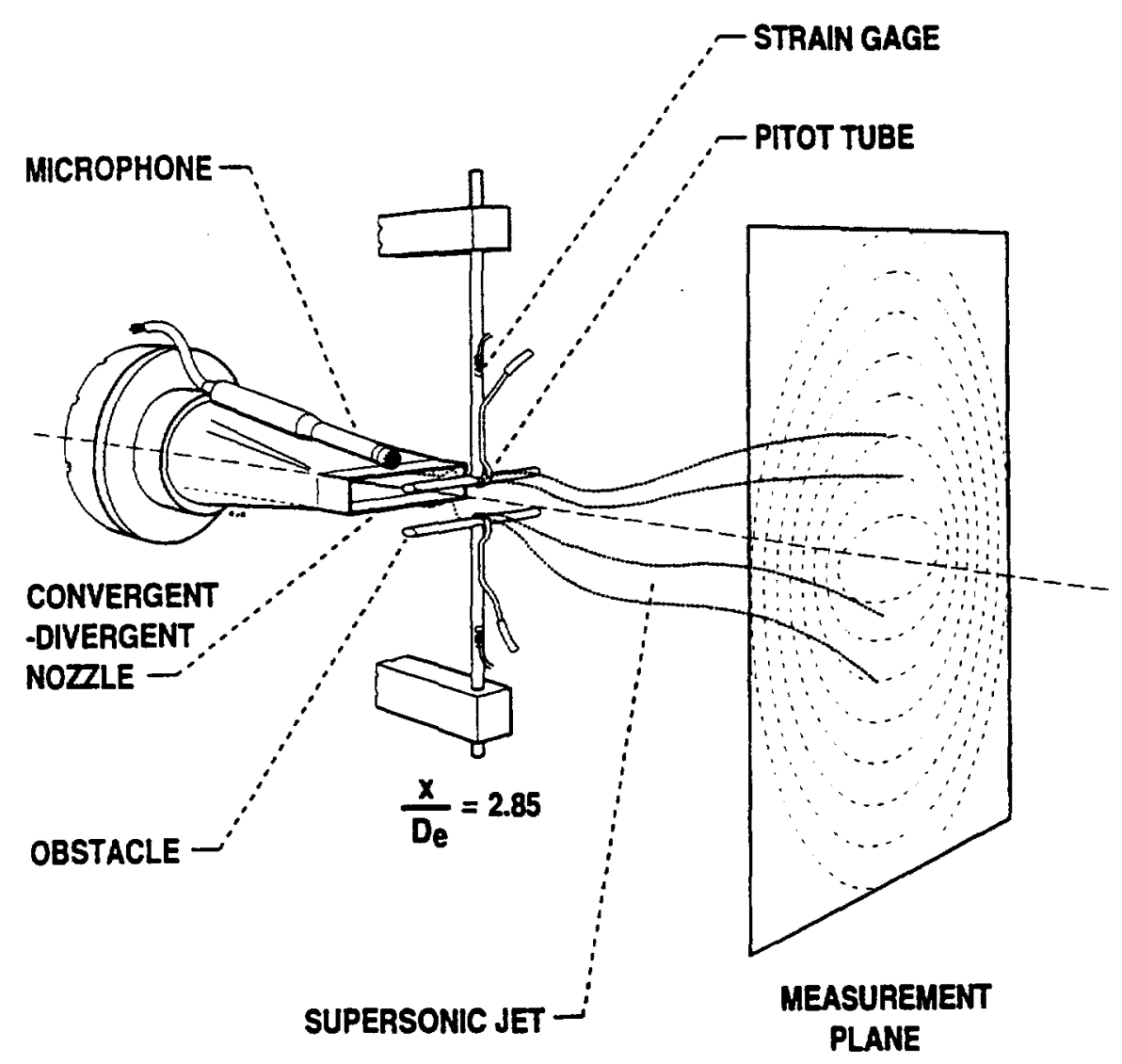

Figure (2) Schematic of impingement tone excitation and measurement set-up.

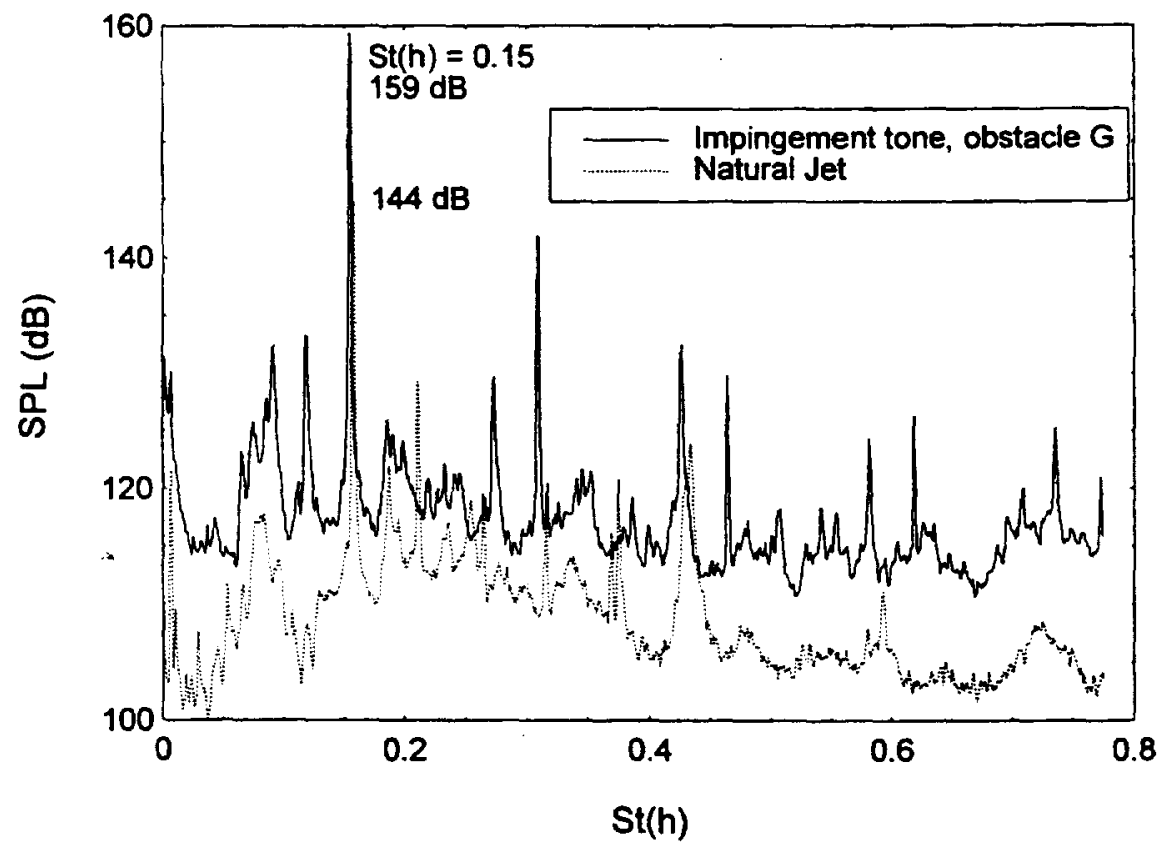

Figure (3) Sound pressure level spectrum measured at jet exit; $M_{j}=1.392, x / h=0, y / h=1, z / h=0$, levels are in $d B$ re. $20 \mu P a$. 

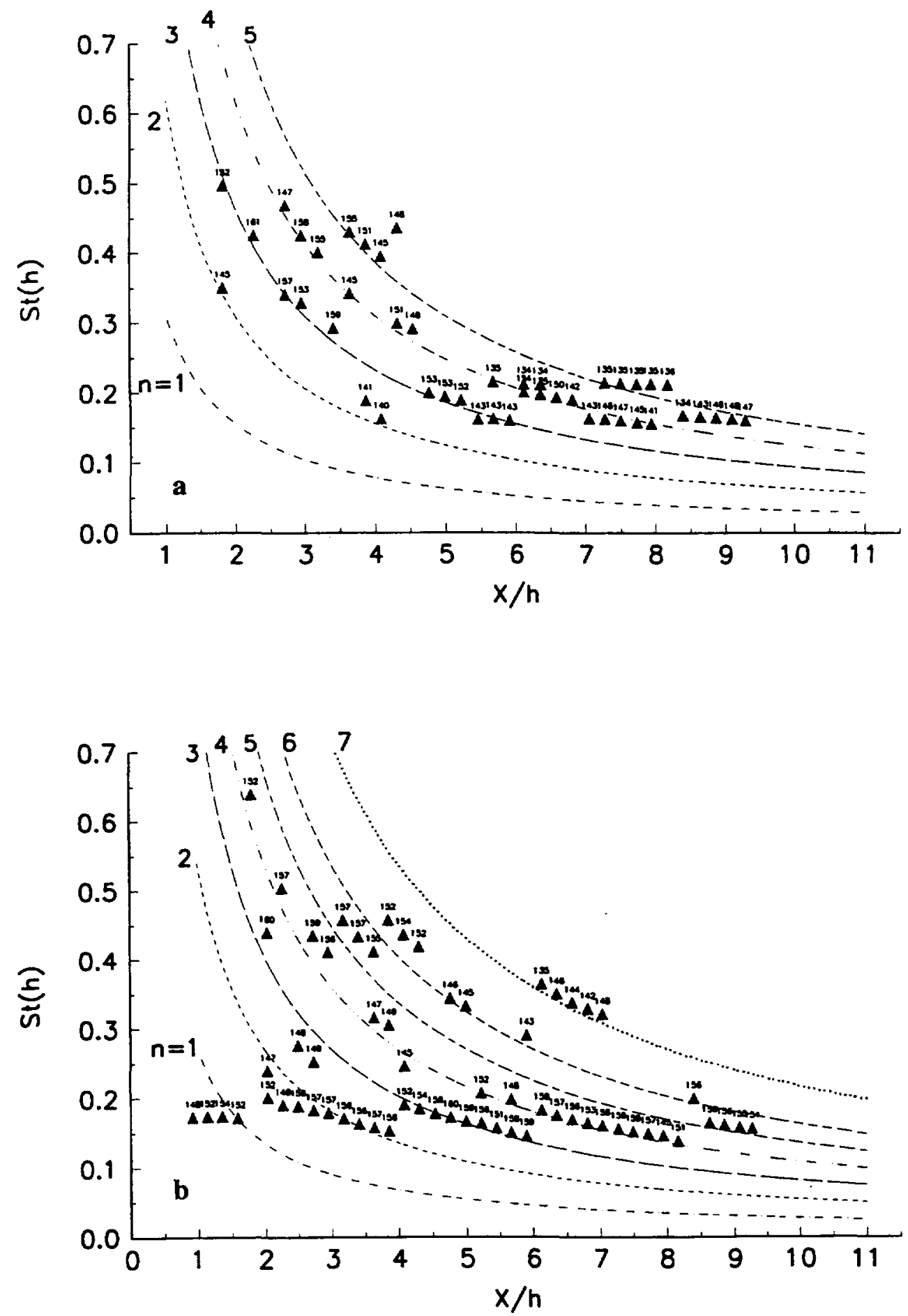

Figure (4) Effect of axial location of obstacle on the Stroubal number of the induced tone; $M_{j}=1.392$, obstacle immersions, $U_{\text {obment }} / U_{j}$, of: (a) 0.36 , (b) 0.72 . A - data for obstacle B (see Table I), the dashed lines are the edgetone stages described by Equation 1. The numbers represent the tone amplitude (dB re. $20 \mu \mathrm{Pa}$ ) measured at $x / h=0, y / h=1, z / h=0$. 


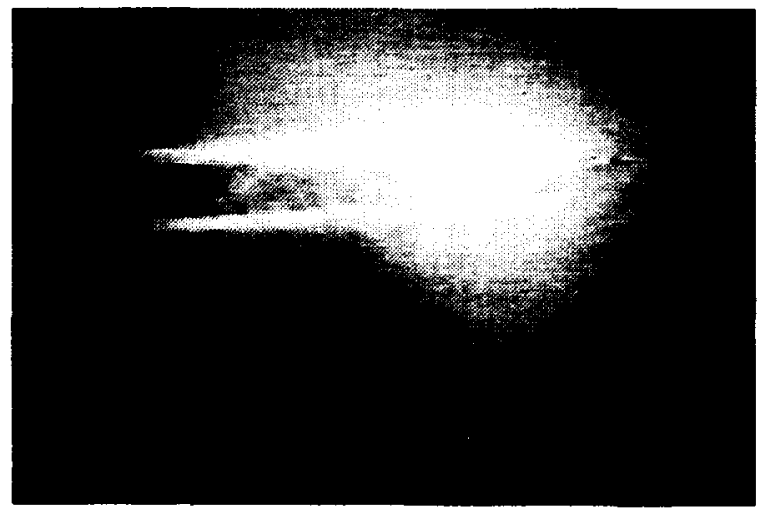

Figure (5) Schlieren photograph of the natural unexcited jet; $M_{j}=1.392$, range covered - $x / h=0$ to 10 .

(a)

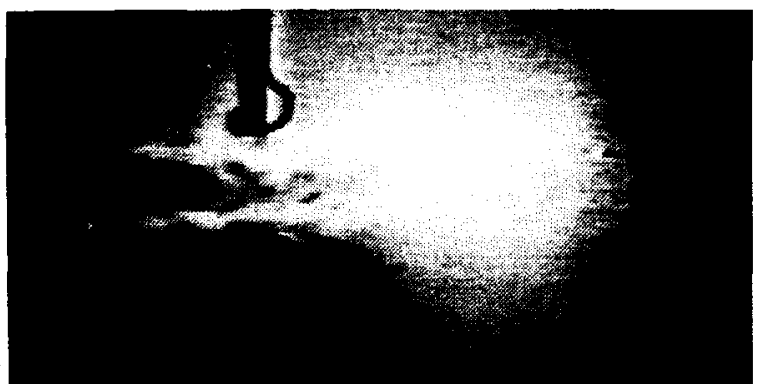

(b)

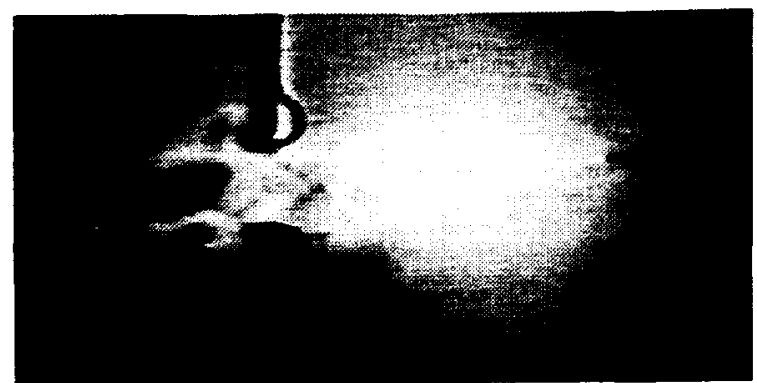

Figure (6) Strobed schlieren photographs of jet excited by impingement tone; $M_{j}=1.392$, obstacle $B$ (see Table I), obstacle at $x / h=2.9$, obstacle immersions, $U_{\text {obsecte }} / U_{j}$, of: (a) 0.36 , (b) 0.72 . (a)

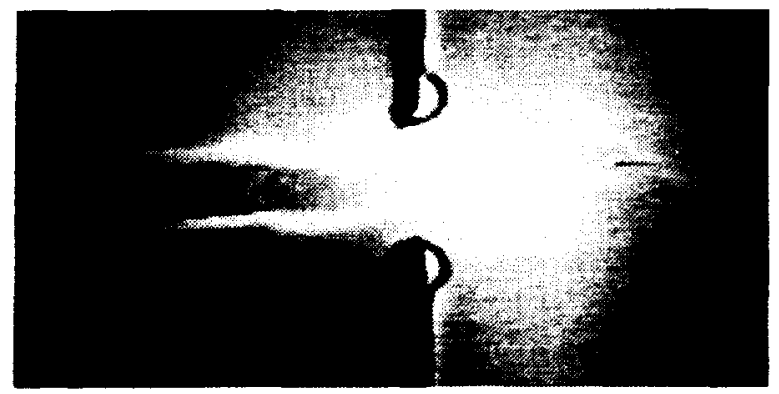

(b)

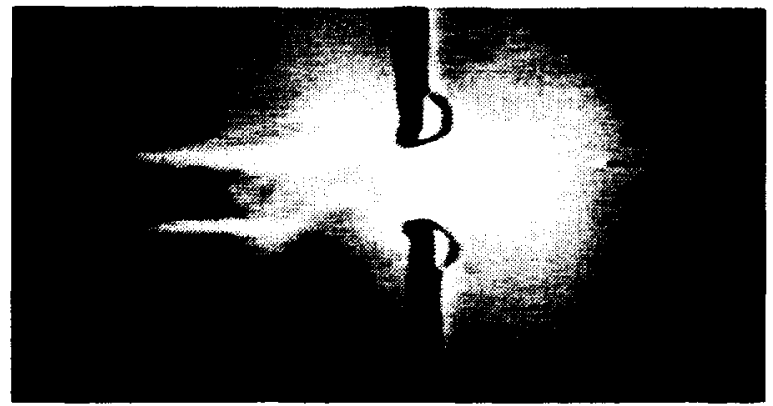

Figure (7) Strobed schlieren photographs of jet excited by impingement tone; $\mathrm{M}_{\mathrm{j}}=1.392$, obstacle $\mathrm{B}$ (see Table I), obstacle at $x / h=5.0$, obstacle immersions, $U_{\text {obslecik }} / U_{j}$, of: (a) 0.36 , (b) 0.72 .

(a)

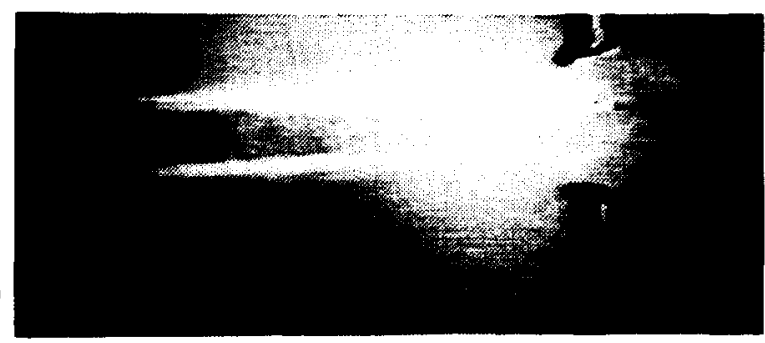

(b)

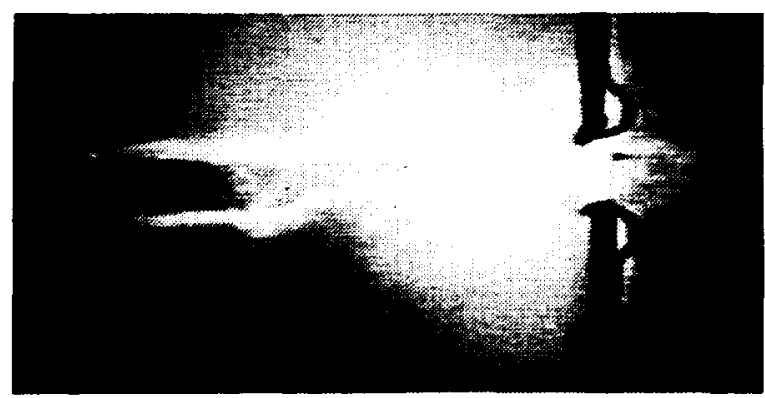

Figure (8) Strobed schlieren photographs of jet excited by impingement tone; $M_{j}=1.392$, obstacle $B$ (see Table I), obstacle at $\mathrm{x} / \mathrm{h}=7.7$, obstacle immersions, $U_{\text {obstack }} / U_{j}$, of: (a) 0.36 , (b) 0.72 . 
a)

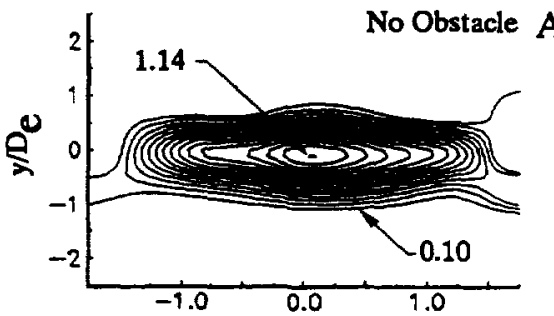

b)

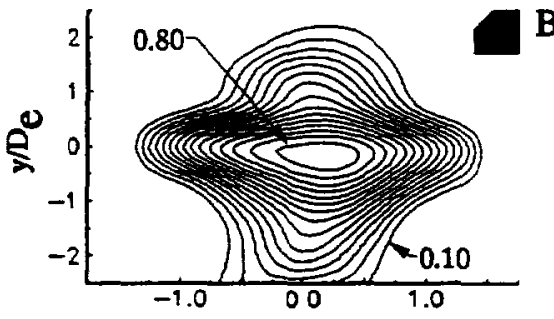

c)

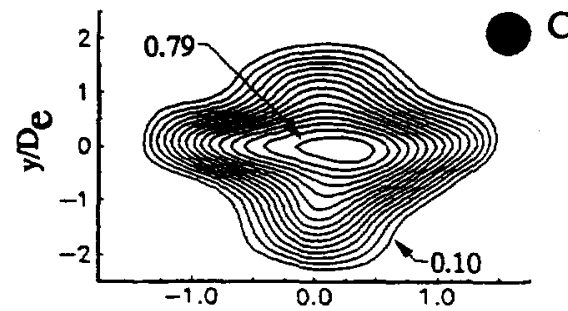

d)

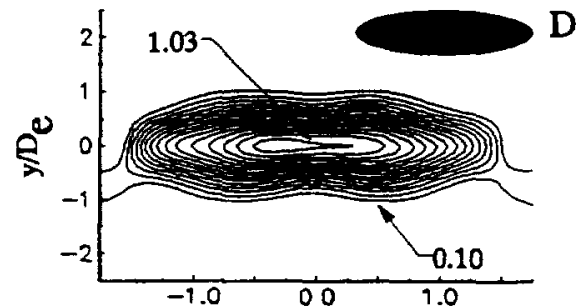

e)

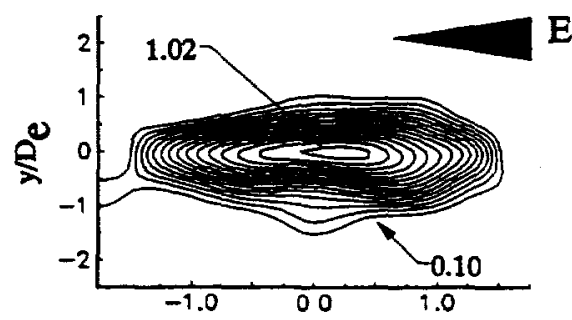

f)

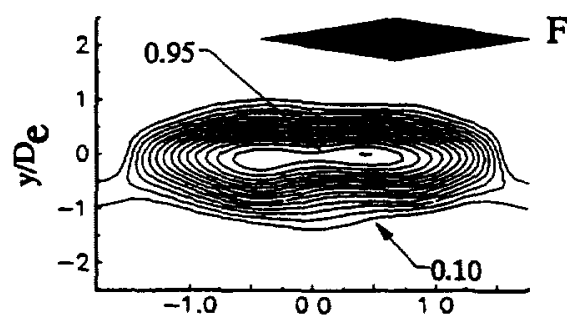

g)

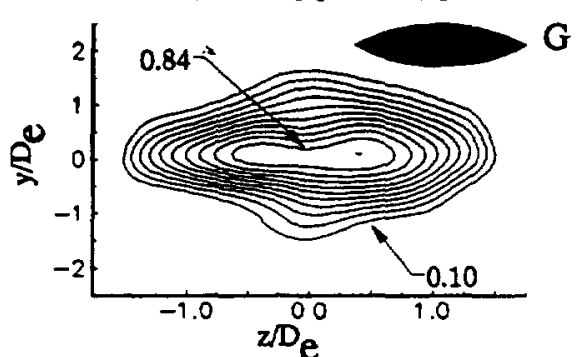

Figure (9) Mach number contours at $x / D_{c}=5$ for obstacles of various geometries compared to the no-obstacle case; $M_{j}=1.392$, contour interval 0.06 , obstacle location $x / h=7.7\left(x / D_{c}=2.85\right)$, obstacle immersion $U_{a n c h} / U_{j}=0.72$. Parts (a)-(g) correspond to the cases and symbols described in Table $I$. a)

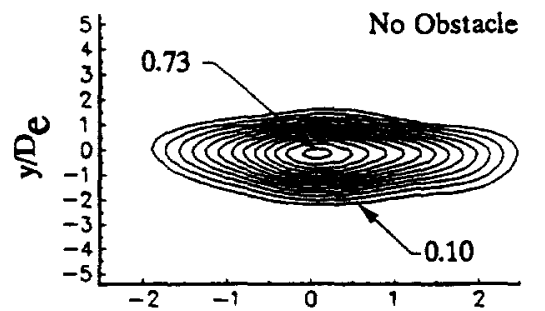

b)

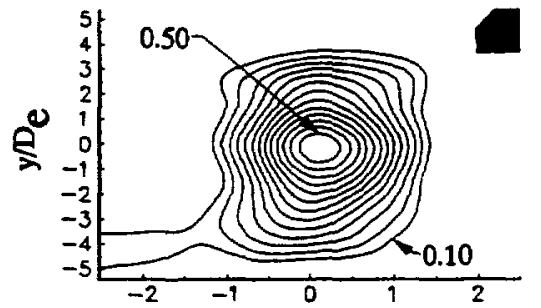

c)

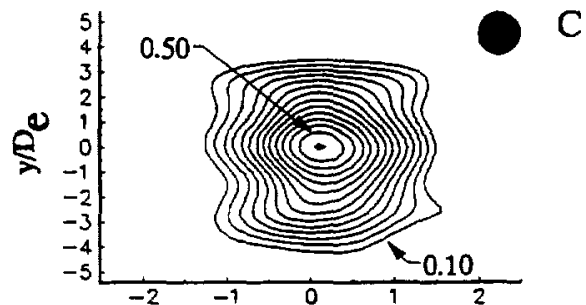

d)

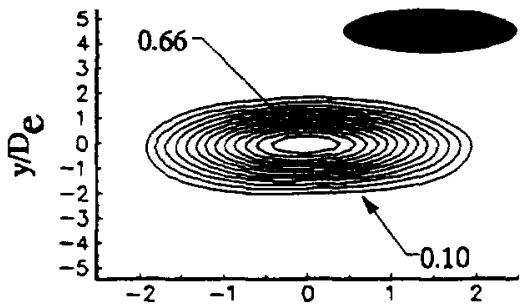

e)

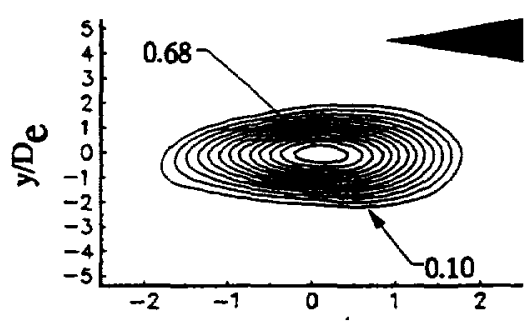

E

f)

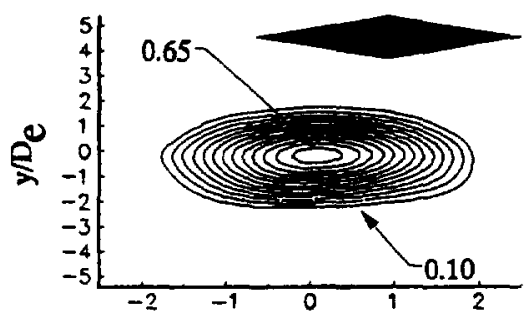

$\mathbf{F}$

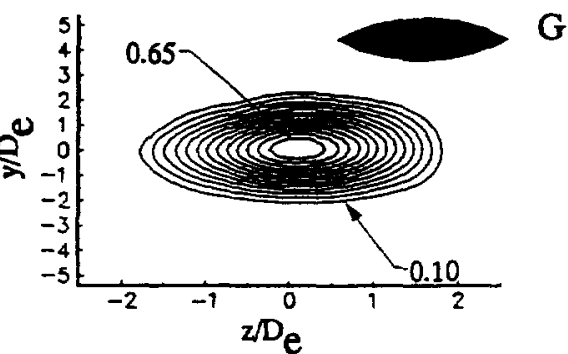

Figure (10) Mach number contours at $x / D_{c}=11$ for obstacles of various geometries compared to the no-obstacle case; $\mathbf{M}_{\mathrm{j}}=1.392$, contour interval 0.04 , obstacle location $x / \mathrm{h}=7.7\left(x / \mathrm{D}_{\mathrm{c}}=2.85\right)$, obstacle immersion $U_{a n a d} / U_{j}=0.72$. Parts (a)-(g) correspond to the cases and symbols described in Table $I$. 


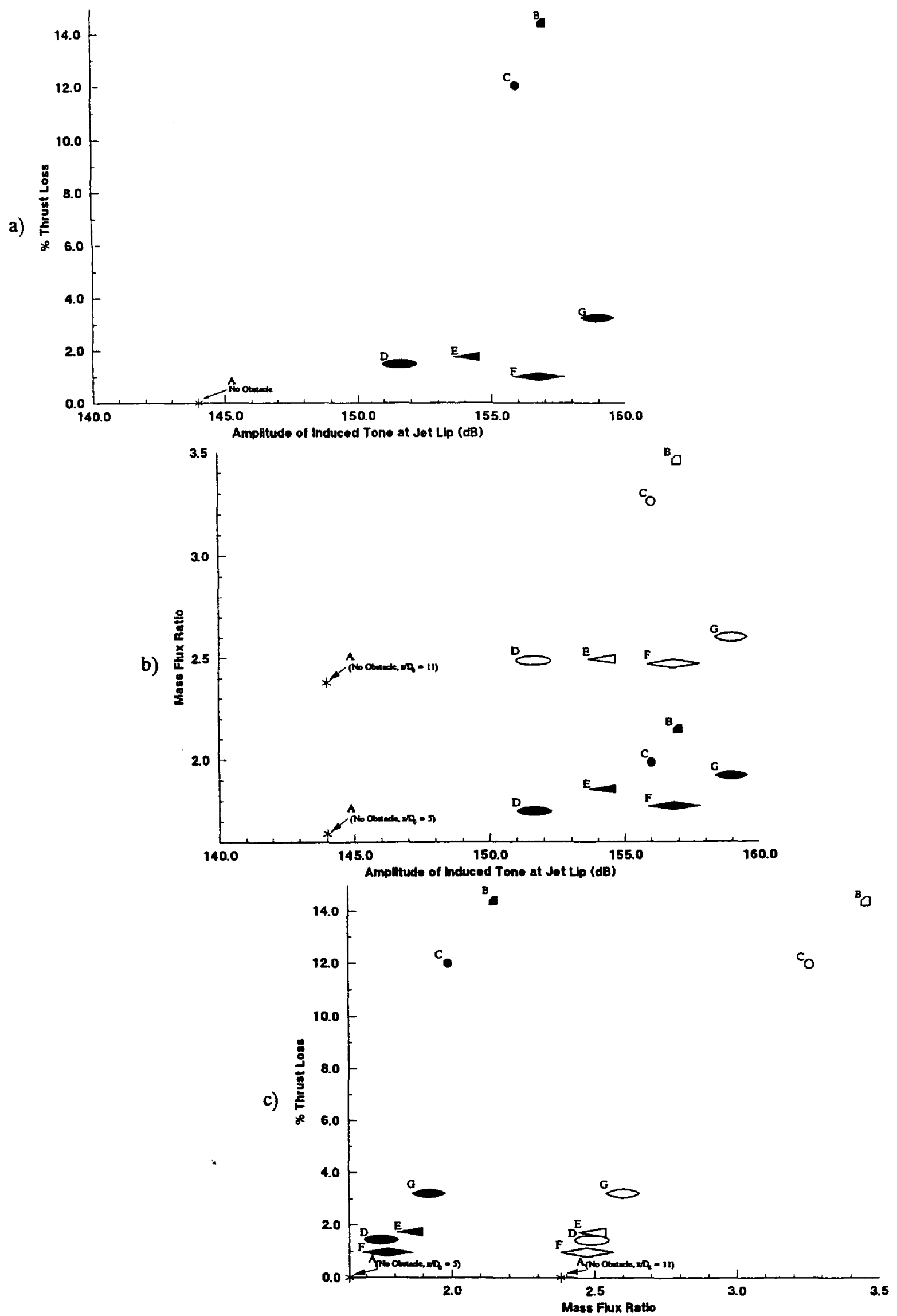

Figure (11) Comparison of mass-flux, thrust loss and impingement tone level for obstacles of various geometries; $M_{j}=1.392$, obstacle location $x / h=7.7$, obstacle immersion $\mathrm{U}_{\text {obssack }} / \mathrm{U}_{\mathrm{j}}=0.72$. (a) Thrust loss versus amplitude of induced tone, (b) Mass-flux ratio versus amplitude of induced tone, (c) Thrust loss versus mass-flux ratio. 
Public reporting burden for this collection of information is estimated to average 1 hour per fesponse, inclucing the time for reviewing instructions, searching existing data sources, gathering and maintaining the data needed, and completing and reviewing the collection of intormation. Send comments regarding this burden estimate or any other aspect of this Davis Highway, Suite 1204, Allington, VA 22202-4302, and to the Otfice of Management and Budget, Paperwork Reduction Project (0704-0189), Washington, DC 20503.

\begin{tabular}{|l|c|r|}
\hline 1. AGENCY USE ONLY (Leave blank) & $\begin{array}{r}\text { 2. REPORT DATE } \\
\text { May } 1994\end{array}$ & $\begin{array}{r}\text { 3. AEPORT TYPE AND DATES COVERED } \\
\text { Technical Memorandum }\end{array}$ \\
\hline
\end{tabular}

\section{TITLE AND SUBTITLE}

Mixing and Noise Benefit Versus Thrust Penalty in Supersonic Jets Using Impingement Tones

6. AUTHOR(S)

Ganesh Raman and Edward J. Rice

\section{PERFORMING ORGANIZATION NAME(S) AND ADDRESS(ES)}

National Aeronautics and Space Administration

Lewis Research Center

Cleveland, Ohio 44135-3191

9. SPONSORING/MONITORING AGENCY NAME(S) AND ADDRESS(ES)

National Aeronautics and Space Administration

Washington, D.C. 20546-0001
5. FUNDING NUMBERS

WU-537-02-22

PERFORMING ORGANIZATION REPORT NUMBER

E-8844

10. SPONSORING/MONITORING AGENCY REPORT NUMBER

NASA TM-106583

AIAA-94-2955

11. SUPPLEMENTARY NOTES

Prepared for the 30th Joint Propulsion Conference cosponsored by the AIAA/ASME/SAE/ASEE, Indianapolis, Indiana, June 27-29, 1994. Ganesh Raman, NYMA, Inc., Engineering Services Division, Brook Park, Ohio 44142 (work funded by NASA Contract NAS3-27186); Edward J. Rice, NASA Lewis Distinguished Research Associate, retired. Responsible person, Ganesh Raman, organization code 2660 , (216) 433-3607.

12a. DISTRIBUTIONAVAILABILITY STATEMENT

12b. DISTRIBUTION CODE

Unclassified - Unlimited

Subject Category 02

13. ABSTRACT (Maximum 200 words)

This paper reports the results of an experimental investigation on the effect of impingement tones generated by obstacles of various geometries on the spreading of a supersonic jet flow. A rectangular supersonic jet was produced using a convergent-divergent nozzle that was operated near its design point (with shocks minimized). The immersion of obstacles in the flow produced an intense impingement tone which then propagated upstream (as feedback) to the jet lip and excited the antisymmetric hydrodynamic mode in the jet, thus setting up a resonant self-sustaining loop. The violent flapping motion of the jet due to excitation of the antisymmetric mode, combined with the unsteady wakes of the obstacles, produced large changes in jet mixing. It was possible to control the frequency and amplitude of the impingement tone excitation by varying the nozzle-to-obstacle distance and the obstacle immersion. By proper shaping of the obstacles it was possible to reduce the thrust penalty significantly.

14. SUBJECT TERMS

Rectangular jet; Screech; Supersonic jet; Acoustics; Jet noise 17

16. PRICE CODE

A03

\begin{tabular}{c|c|c}
\hline $\begin{array}{c}\text { 17. SECURITY CLASSIFICATION } \\
\text { OF REPORT } \\
\text { Unclassified }\end{array}$ & $\begin{array}{c}\text { 18. SECURITY CLASSIFICATION } \\
\text { OF THIS PAGE } \\
\text { Unclassified }\end{array}$ & $\begin{array}{c}\text { 19. SECURITY CLASSIFICATION } \\
\text { OF ABSTRACT } \\
\text { Unclassified }\end{array}$ \\
\hline
\end{tabular}

